\title{
Evaluation of nutritional status and eating behavior in Romanian pediatric population
}

\author{
Simona Loredana Vasilache ${ }^{1,2}$, Anastasia Boaghi'2, Raluca-Monica Pop², \\ Claudia Banescu ${ }^{3}$, Valeriu Moldovan ${ }^{3}$, Carmen Duicu', \\ Ionela Maria Pascanu ${ }^{2,4}$, Oana Marginean ${ }^{1}$ \\ ${ }^{1}$ Department of Pediatrics, "George Emil Palade" University of Medicine, Pharmacy, Science and \\ Technology, Tg. Mures, Romania \\ ${ }^{2}$ Department of Endocrinology, Mures County Hospital, Tg. Mures, Romania \\ ${ }^{3}$ Department of Genetics, "George Emil Palade" University of Medicine, Pharmacy, Science and \\ Technology, Tg. Mures, Romania \\ ${ }^{4}$ Department of Endocrinology, "George Emil Palade" University of Medicine, Pharmacy, Science and \\ Technology, Tg. Mures, Romania
}

\begin{abstract}
Objectives. Numerous factors have been associated with hight prevalence of obesity, nutrition being the most important factor. The aim of this study was to evaluate the eating behavior of school children in Targu Mures and to evaluate the impact on auxological parameters.

Material and method. The study included 213 children divided in 2 groups (107 females, 106 males), aged 5-18, evaluated in the Pediatrics I and Endocrinology Clinic in Târgu Mureș. The evaluation included: auxological data, body composition using bioimpedance. Participants reported eating behavior using a 126-item food frequency questionnaire. The results were classified as concentrated sweets, fats, meat, fruits and vegetables, cereals and dairy products.

Results. There are no statistically significant differences between the 2 groups regarding the food pyramid. However, in boys, there are statistically significant correlations between fat consumption and weight $(r=0.198$, $p=0.042)$ and body water $(r=0.209, p=0.044)$, and the consumption of meat correlates with weight $(r=0.249$, $p=0.010)$, abdominal circumference $(r=0.258, p=0.008)$ and waist-height ratio $(r=0.193, p=0.048)$. In girls, there is no singnificant correlations between intake of studied food group and anthropometric parameters.

Conclusions. The results highlight the importance of eating behavior, which has a major impact in obesity prevalence. In our study, there are correlations between concentrated fats and meat consumption and adiposity markers in boys. Prospective studies are needed to identify how different types of food related to body composition and central obesity in pediatric population.
\end{abstract}

Keywords: eating behavior, obesity, pediatric population

\author{
Abbreviations \\ NHANES - National Health and Nutrition Examination Survey \\ BMI - body mass index \\ WHtR - weight-height raport \\ TST - tricipital skinfold thickness \\ FFQ - food frequency questionnaire
}

\section{INTRODUCTION}

Numerous factors have been associated with an increase in the prevalence of overweight and obesity among the pediatric population, including social, dietary and behavioral factors. Diet is the most important lifestyle factor associated with overweight and obesity, but studies evaluating the relationship between obesity and eating behavior are limited and controversial [1]. To manage this public health prob- 
lem, it is important that attention be directed to the pediatric population because during this period the eating behavior is defined.

For a child to grow healthy and harmonious, their diet should include all food categories. Dairy products are considered a food group known as a healthy source of nutrients, they provide protein, vitamins, calcium and magnesium, which supports children growth [2]. Cereal based products are one of the most significant foods in the world, being important sources of fiber. [3]. Fruits and vegetables are also an important source of fiber. Eating fruits and vegetables is an important strategy to reduce obesity, however a study based on NHANES data showed that $95 \%$ of school children consume fewer vegetables and $60 \%$ consume fewer fruits than recommended [4]. Protein are also important for normal development of children and meat is an important source of high quality protein, but excessive meat consumption is often related to overweight, obesity and an increased risk of chronic disease [5]. Also, eating sweet and fat foods brings an increased calorie intake, leading to obesity and overweight in the pediatric population [6].

The aim of this study was to evaluate the eating behavior of school children in Târgu Mureş and to evaluate its impact on growth of these children.

\section{MATERIAL AND METHOD}

The study included 213 children divided in 2 groups: 107 females, 106 males, aged 5-18 evaluated in Tg. Mures, in Departament of Pediatrics I and Department of Endocrinology. Anthropometric data (weight, height, body mass index - BMI, waist circumference, waist-height ratio WHtR, tricipital skinfold thickness - TST), body composition using bioimpedance (fat mass, free fat mass, quantity of body water), were evaluated. Participants reported eating behavior using a semi-quantitative food frequency questionnaire (FFQ) with 126 items. Consumption frequencies are used for each food from "never" or "less than once a month" to "more than 6 times a day". Each item belongs to one or more of the 6 main food groups: cereals, fruits and vegetables, dairy, meat, fats, concentrated sweets; analyzing the frequencies of food consumption, the individual food pyramid was created.

This questionnaire is based on the questionnaire used in the National Health and Nutrition Examination Survey III (NHANES III) [7] and adapted to local eating habits. The ideal food pyramid include: at least 6 portions of cereals; minimum 5 portions of fruits and vegetables; maximum 3 portions of milk; maximum 2 portions of meat and protein; maximum 2 portions of fat; maximum 1 portion of concentrated sweets [8].

All patients included in the study completed an informed consent. The study was approved by the University's Ethics Committee (No. 7/2016).

\section{RESULTS}

Evaluating the general data of the two groups, there is statistically significant differences regarding weight $(p=0.023)$, tricipital skinfold $(p=0.004)$ and all elements of body composition (fat mass $p=0.008$, muscle mass $\mathrm{p}=0.005$, body water $\mathrm{p}=0.007$ ), however no differences regarding BMI were observed $(\mathrm{p}=0.343)($ Table 1$)$.

TABLE 1. Anthropometric and food pyramid comparison between study groups

\begin{tabular}{|l|c|c|c|}
\hline & Females (107) & Males (106) & p value \\
\hline Height DS & $0.158 \pm 1.588$ & $0.816 \pm 6.300$ & 0.296 \\
\hline Weight SD & $1.505 \pm 1.523$ & $1.963 \pm 1.402$ & 0.023 \\
\hline BMI SD & $1.275 \pm 2.721$ & $1.683 \pm 3.506$ & 0.343 \\
\hline Waist SD & $1.733 \pm 1.111$ & $1.955 \pm 1.183$ & 0.160 \\
\hline WHtR & $0.524 \pm 0.008$ & $0.547 \pm 0.086$ & 0.052 \\
\hline TST SD & $0.971 \pm 1.905$ & $2.173 \pm 3.817$ & 0.004 \\
\hline Fat mass (\%) & $29.06 \pm 8.755$ & $25.15 \pm 11.571$ & 0.008 \\
\hline Free fat mass (kg) & $34.25 \pm 9.394$ & $39.28 \pm 14.327$ & 0.003 \\
\hline Muscle mass (kg) & $33.2 \pm 8.571$ & $37.87 \pm 13.948$ & 0.005 \\
\hline Body water (\%) & $51.41 \pm 7.106$ & $54.42 \pm 8.609$ & 0.007 \\
\hline Sweet products & $2.94 \pm 4.253$ & $2.99 \pm 3.388$ & 0.921 \\
\hline Fat products & $5.51 \pm 6.569$ & $5.63 \pm 5.394$ & 0.886 \\
\hline Meat products & $5.26 \pm 8.645$ & $5.18 \pm 6.551$ & 0.941 \\
\hline Diary products & $3.20 \pm 2.442$ & $3.51 \pm 3.176$ & 0.429 \\
\hline Cereal products & $6.51 \pm 7.313$ & $6.49 \pm 5.173$ & 0.985 \\
\hline Fruits and \\
vegetables products
\end{tabular}

BMI - body mass index, WHtR - waist per height ratio, TST - tricipita skinfold thickness, SD - standard deviation, $\mathrm{p}=$ statistical significance was obtained if $p<0.05$

Regarding food pyramids of the 2 groups studied, no statistically significant differences were obtained related to the categories of food consumed, sweets $(\mathrm{p}=0.921)$, concentrated fats $\mathrm{p}=0.886)$, meat $(\mathrm{p}=0.941)$, dairy products $(\mathrm{p}=0.429)$, cereals $(p=0.985)$, fruits and vegetables $(p=0.980)($ Table 1$)$.

In girls, there is no significant correlations between intake of studied food group and anthropometric parameters (Table 2).

However, in boys group, the results revealed significant correlations between fat products intake and weight $(\mathrm{r}=0.198, \mathrm{p}=0.042)$ and body water $(\mathrm{r}=0.209, \mathrm{p}=0.044)$ and the consumption of meat correlates with weight $(r=0.249, \mathrm{p}=0.010)$, abdominal circumference $(\mathrm{r}=0.258, \mathrm{p}=0.008)$ and waistheight ratio $(r=0.193, p=0.048)($ Table 3$)$. 
TABLE 2. Correlation between food pyramid and auxologic paramaters in female group

\begin{tabular}{|l|c|c|c|c|c|c|}
\hline & $\begin{array}{c}\text { Sweet } \\
\text { products }\end{array}$ & $\begin{array}{c}\text { Fat } \\
\text { products }\end{array}$ & $\begin{array}{c}\text { Meat } \\
\text { products }\end{array}$ & $\begin{array}{c}\text { Diary } \\
\text { products }\end{array}$ & $\begin{array}{c}\text { Cereal } \\
\text { products }\end{array}$ & $\begin{array}{c}\text { Fruits and } \\
\text { vegetables products }\end{array}$ \\
\hline \multirow{2}{*}{ Height DS } & $p=0.938$ & $p=0.650$ & $p=0.259$ & $p=0.060$ & $p=0.978$ & $p=0.710$ \\
& $r=-0.008$ & $r=0.045$ & $r=0.111$ & $r=0.184$ & $r=-0.003$ & $r=0.036$ \\
\hline \multirow{2}{*}{ Weight SD } & $p=0.110$ & $p=0.649$ & $p=0.640$ & $p=0.305$ & $p=0.307$ & $p=0.647$ \\
& $r=-0.156$ & $r=-0.045$ & $r=0.046$ & $r=0.101$ & $r=-0.100$ & $r=-0.045$ \\
\hline \multirow{2}{*}{ BMI SD } & $p=0.311$ & $p=0.760$ & $p=0.654$ & $p=0.824$ & $p=0.732$ & $p=0.523$ \\
& $r=-0.099$ & $r=0.030$ & $r=0.044$ & $r=-0.022$ & $r=0.034$ & $r=-0.063$ \\
\hline \multirow{2}{*}{ Waist SD } & $p=0.129$ & $p=0.590$ & $p=0.621$ & $p=0.949$ & $p=0.409$ & $p=0.382$ \\
& $r=-0.149$ & $r=-0.053$ & $r=0.049$ & $r=0.006$ & $r=-0.081$ & $r=-0.086$ \\
\hline \multirow{2}{*}{ WHtR } & $p=0.176$ & $p=0.376$ & $p=0.842$ & $p=0.652$ & $p=0.289$ & $p=0.370$ \\
& $r=-0.133$ & $r=-0.087$ & $r=-0.020$ & $r=-0.044$ & $r=-0.104$ & $r=-0.088$ \\
\hline \multirow{2}{*}{ TST SD } & $p=0.149$ & $p=0.253$ & $p=0.391$ & $p=0.509$ & $p=0.133$ & $p=0.721$ \\
& $r=-0.143$ & $r=-0.113$ & $r=-0.085$ & $r=0.066$ & $r=-0.148$ & $r=-0.035$ \\
\hline \multirow{2}{*}{ Fat mass (\%) } & $p=0.106$ & $p=0.581$ & $p=0.806$ & $p=0.953$ & $p=0.273$ & $p=0.336$ \\
& $r=-0.161$ & $r=-0.055$ & $r=0.025$ & $r=0.006$ & $r=-0.109$ & $r=-0.096$ \\
\hline \multirow{2}{*}{ Free fat mass (kg) } & $p=0.322$ & $p=0.672$ & $p=0.769$ & $p=0.897$ & $p=0.094$ & $p=0.347$ \\
& $r=-0.099$ & $r=-0.042$ & $r=-0.029$ & $r=0.013$ & $r=-0.167$ & $r=-0.094$ \\
\hline \multirow{2}{*}{ Muscle mass (kg) } & $p=0.251$ & $p=0.573$ & $p=0.669$ & $p=0.830$ & $p=0.104$ & $p=0.326$ \\
& $r=-0.115$ & $r=-0.056$ & $r=-0.043$ & $r=-0.022$ & $r=-0.162$ & $r=-0.098$ \\
\hline \multirow{2}{*}{ Body water (kg) } & $p=0.267$ & $p=0.605 r=$ & $p=0.726$ & $p=0.920$ & $p=0.130$ & $p=0.278$ \\
& $r=-0.111$ & -0.052 & $r=-0.0 .35$ & $r=-0.010$ & $r=-0.151$ & $r=-0.108$ \\
\hline
\end{tabular}

$\mathrm{BMI}$ - body mass index, WHtR - waist per height ratio, TST - tricipital skinfold thickness, SD - standard deviation, $p=$ statistical significance was obtained if $p<0.05, r=$ correlation coefficient

TABLE 3. Correlation between food pyramid and auxologic paramaters in male group

\begin{tabular}{|c|c|c|c|c|c|c|}
\hline & $\begin{array}{c}\text { Sweet } \\
\text { products }\end{array}$ & $\begin{array}{c}\text { Fat } \\
\text { products }\end{array}$ & $\begin{array}{c}\text { Meat } \\
\text { products }\end{array}$ & $\begin{array}{c}\text { Diary } \\
\text { products }\end{array}$ & $\begin{array}{c}\text { Cereal } \\
\text { products }\end{array}$ & $\begin{array}{c}\text { Fruits and } \\
\text { vegetables products }\end{array}$ \\
\hline \multirow{2}{*}{ Height DS } & $p=0.701$ & $p=0.671$ & $p=0.919$ & $p=0.817$ & $p=0.886$ & $p=0.412$ \\
& $r=-0.038$ & $r=-0.042$ & $r=-0.010$ & $r=0.023$ & $r=-0.014$ & $r=-0.081$ \\
\hline \multirow{2}{*}{ Weight SD } & $p=0.877$ & $p=0.042$ & $p=0.010$ & $p=0.122$ & $p=0.259$ & $p=0.300$ \\
& $r=-0.015$ & $r=0.198$ & $r=0.249$ & $r=0.151$ & $r=0.111$ & $r=0.102$ \\
\hline \multirow{2}{*}{ BMI SD } & $p=0.423$ & $p=0.893$ & $p=0.689$ & $p=0.753$ & $p=0.925$ & $p=0.900$ \\
& $r=-0.079$ & $r=-0.013$ & $r=0.039$ & $r=-0.031$ & $r=-0.009$ & $r=-0.012$ \\
\hline \multirow{2}{*}{ Waist SD } & $p=0.982$ & $p=0.099$ & $p=0.008$ & $p=0.334$ & $p=0.341$ & $p=0.212$ \\
& $r=-0.002$ & $r=0.161$ & $r=0.258$ & $r=0.095$ & $r=0.093$ & $r=0.122$ \\
\hline \multirow{2}{*}{ WHtR } & $p=0.893$ & $p=0.095$ & $p=0.048$ & $p=0.055$ & $p=0.407$ & $p=0.482$ \\
& $r=-0.013$ & $r=0.163$ & $r=0.193$ & $r=0.187$ & $r=0.081$ & $r=0.069$ \\
\hline \multirow{2}{*}{ TST SD } & $p=0.477$ & $p=0.892$ & $p=0.370$ & $p=0.098$ & $p=0.876$ & $p=0.236$ \\
& $r=-0.073$ & $r=0.014$ & $r=0.092$ & $r=0.169$ & $r=-0.016$ & $r=0.115$ \\
\hline \multirow{2}{*}{ Fat mass (\%) } & $p=0.318$ & $p=0.715$ & $p=0.347$ & $p=0.673$ & $p=0.613$ & $p=0.871$ \\
& $r=-0.105$ & $r=0.038$ & $r=0.099$ & $r=0.044$ & $r=0.053$ & $r=0.017$ \\
\hline \multirow{2}{*}{ Free fat mass (kg) } & $p=0.214$ & $p=0.075$ & $p=0.055$ & $p=0.201$ & $p=0.264$ & $p=0.583$ \\
& $r=0.130$ & $r=0.186$ & $r=0.200$ & $r=-0.134$ & $r=0.117$ & $r=0.058$ \\
\hline Muscle mass (kg) & $p=0.258$ & $p=0.098$ & $p=0.075$ & $p=0.211$ & $p=0.331$ & $p=0.638$ \\
& $r=0.119$ & $r=0.172$ & $r=0.185$ & $r=-0.131$ & $r=0.120$ & $r=0.049$ \\
\hline Body water (kg) & $p=0.213$ & $p=0.044 r=$ & $p=0.087$ & $p=0.309$ & $p=0.204$ & $p=0.643$ \\
& $r=0.130$ & 0.209 & $r=0.179$ & $r=-0.107$ & $r=0.133$ & $r=0.049$ \\
\hline
\end{tabular}

$\mathrm{BMI}$ - body mass index, WHtR - waist per height ratio, TST - tricipital skinfold thickness, SD - standard deviation, $\mathrm{p}=$ statistical significance was obtained if $p<0.05, r=$ correlation coefficient

Regarding the consumption of dairy products, cereals, fruits and vegetables, no statistically signifi- cant correlations were observed with the auxological parameters in males (Table 3). 


\section{DISCUSSIONS}

Childhood and adolescent obesity continues to be a significant challenge to public health. Eating behaviour is the most important lifestyle factor associated with overweight and obesity.

The literature has shown in the pediatric population a greater predisposition to consume sweet and high-fat foods [6]. There are studies that have shown that those children who consume sweet and high-fat foods are 2 times more likely to develop obesity $[9,10]$. Bao et al. demonstrated in female patients that BMI and WHtR increase with the consumption of high-fat products [11]. Our study showed a significant correlation between fat intake and weight and body water, but only in male patients.

Food marketing plays an important role through increasing children's access to obesogenic foods [1]. The possibility to have access to unhealthy food such us snack and soft drinks in schools was correlated with lower fruits and vegetable consumption, higher intake of calories from total and saturated fat, and a higher BMI score [1]. Diets rich in fruits and vegetables play an important role in terms of harmonious growth of children [12], some studies have shown a lower BMI in patients who ate fruits and vegetables [13]. However in our study we found no correlations between fruit and vegetable consumption and analyzed parameters.

The consumption of fiber is on the base of food pyramid and along with fruits and vegetables, an excellent source of fiber are cereals. Regarding the evaluation of cereal consumption studies are limited in the pediatric population, especially when we discuss the consumption of these products related to gender. The results of other studies are controversial. There are results that have shown that fiber intake leads to an increase in fat mass percentage [14], contrary to other studies [15]. In our study there is no significant correlation between cereal consumption and anthropometric parameters. The different results may be based on the modern lifestyle in recent years, an important development of food marketing that combines cereals with concentrated sweets being observed [16].

Regarding meat consumption, there are studies in the literature with contradictory results, some authors have shown a decrease in BMI in patients with a consumption of 5 servings of meat per week [17], in contradiction with other studies which underlined an association between meat consumption and the appearance of adiposity [18]. Similarly, our results revealed a significant correlation between meat consumption and weight, abdominal circumference and WHtR, but only in boys group.

Studies have shown discrepant results regarding the involvement of dairy products in the occurrence of obesity in children and adolescents, which continue to be one of the most controversial food categories $[19,20]$, Some studies have shown that dairy intake influences growth in both gender, encountering significant correlations between dairy consumption and fat mass, free fat mass and WHtR and emphasizing their contribution in central obesity development in males patients [21]. The majority of studies suggest that dairy intake has a protective effect, preventing increased BMI and fat mass percentage, in both genders [22]. However, there are studies that have shown that there is no correlation between dairy consumption and adiposity [23], similar to our study.

Finally, we highlight some limitations of our study: lack of evaluation of physical activity and the possibility of reporting errors during the use of the food frequency questionnaire. FFQ has an increased subjectivity, which is based on differences between the estimated portion size and the total amount of food actually consumed.

\section{CONCLUSIONS}

The results highlight the importance of eating behavior, which has a major impact on metabolic factors. Meat and fat products intake were significantly correlated with weight and adiposity markers in male Romanian children. The role of meat and fat products consumption regarding central adiposity pattern and body composition seems to be gender specific. It is important to address nutrition early in the life span for Romanian youth to increase long-term preventive health behaviors and reduce long-term risks. Further studies are needed for a better understanding of these correlations and subsequent development of proper nutritional strategies.

Conflict of interest: none declared Financial support: none declared

\section{REFERENCES}

1. Hamulka J, Wadolowska L, Hoffmann M et al. Effect of an Education Program on Nutrition Knowledge, Attitudes toward Nutrition, Diet Quality, Lifestyle, and Body Composition in Polish Teenagers. The ABC of Healthy Eating Project: Design, Protocol, and Methodology. Nutrients. 2018;10:439.
2. Dror D. Dairy consumption and pre-school, school-age and adolescent obesity in developed countries: A systematic review and meta-analysis. Obes Rev. 2014;15:516-527.

3. Mobley A, Slavin J, Hornick B. The Future of Recommendations on Grain Foods in Dietary Guidance. J Nutr. 2013;143:1527S-1532S. 
4. Kim S, Moore L, Galuska D, et al. Vital signs: fruit and vegetable intake among children - United States, 2003-2010. MMWR Morb Mortal Wkly Rep. 2014;63:671-676.

5. Salter A. The effects of meat consumption on global health. Rev Sci Tech Off Int Epiz. 2018;37(1):47-55.

6. Sobek G, Łuszczki E, Dabrowski M, et al. Preferences for Sweet and Fatty Taste in Children and Their Mothers in Association with Weight Status. Int J Environ Res Public Health. 2020;17:538.

7. National Center for Health Statistics, CDC. National Health and Nutrition Examination Survey. About the National Health and Nutrition Examination Survey, [Internet], 2015. Available from: www.cdc.gov/ nchs/nhanes/about_nhanes.htm.

8. Petri (Pop) R, Dogaru G. Abordarea standardizată a pacientului cu obezitate abdominală (Teză de doctorat). University Press. 2014; 25-45.

9. Sobek G, Łuszczki E, Dabrowski M, et al. Preferences for Sweet and Fatty Taste in Children and Their Mothers in Association with Weight Status. Int J Environ Res Public Health. 2020;17:538.

10. Scholz A, Navarrete-Muñoz E, García-de-la-Hera M, et al. Association between trans fatty acid intake and overweight including obesity in 4 to 5 -year-old children from the INMA study. Pediatr Obes. 2019;14(9):e12528.

11. Bao X, Duan R, Yang M, et al. Consumptions of Meat, Dietary Fat, and Fatty-acids and Prevalence of Overweight/Obesity in Children and Adolescents - a Cross-sectional Survey in Chengdu. Sichuan Da Xue Xue Bao Yi Xue Ban. 2017;48(1):96-100.

12. McGlone K, Banna J. A Unique, Innovative, Easy-to-Use Program to Improve Young Children's Attitudes About and Consumption of Fruits and Vegetables. Am J Lifestyle Med. 2019;14(1):24-27.

13. Doa B, Yanga C-H, Lopeza N, et al. Investigating the momentary association between maternal support and children's fruit and vegetable consumption using ecological momentary assessment. Appetite. 2020;150:104667.

14. Lin Y, Huybrechts I, Vereecken C, et al. Dietary fiber intake and its association with indicators of adiposity and serum biomarkers in
European adolescents: the HELENA study. European Journal of Nutrition. 2015;54(5):771-82.

15. Damsgaard C, Biltoft-Jensen A, Tetens I, et al. Whole-Grain Intake, Reflected by Dietary Records and Biomarkers, Is Inversely Associated with Circulating Insulin and Other Cardiometabolic Markers in 8- to 11-Year-Old Children. J Nutr. 2017;147(5):816-824.

16. Fayet-Moore F, McConnell A, Tuck K, et al. Breakfast and Breakfast Cereal Choice and Its Impact on Nutrient and Sugar Intakes and Anthropometric Measures among a Nationally Representative Sample of Australian Children and Adolescents. Nutrients. 2017; 9:1045.

17. Kim G, Shin S, Lee J, et al. Red meat and chicken consumption and its association with high blood pressure and obesity in South Korean children and adolescents: a cross-sectional analysis of KSHES, 2011-2015. Nutrition Journal. 2017;16:31.

18. Shin S. Association of Meat Intake with Overweight and Obesity among School-aged Children and Adolescents. Journal of Obesity \& Metabolic Syndrome. 2017;26:217-226.

19. Crichton G, Alkerwi A. Whole-fat dairy food intake is inversely associated with obesity prevalence: Findings from the observation of cardiovascular risk factors in Luxembourg Study. Nutr Res. 2014; 34:936-943.

20. Rehm C, Drewnowski A, Monsivais P. Potential population-level nutritional impact of replacing whole and reduced-fat milk with low-fat and skim milk among us children aged 2-19 years. J Nutr Educ Behav. 2015;47:61-68.

21. Nezami M, Segovia-Siapco G, Beeson W, et al. Associations between Consumption of Dairy Foods and Anthropometric Indicators of Health in Adolescents. Nutrients. 2016:8:427.

22. Abreu S, Santos R, Moreira C, et al. Milk intake is inversely related to body mass index and body fat in girls. Eur J Pediatr. 2012; 171:1467-1474.

23. Fiorito $L$, Mitchell $D$, Smiciklas-Wright $H$, et al. Girls calcium intake is associated with bone mineral content during middle childhood. J Nutr. 2006;136:1281-1286. 